\title{
Research on Distribution Network Control Integration Based on the Smart Grid Environment
}

\author{
Shanlin Cui \\ Jinzhou Power Supply Branch \\ State Grid Liaoning Electric Power Supply Co. Ltd \\ Jinzhou, China \\ cuisljz@163.com
}

\begin{abstract}
With the continuous development of the social economy, the demand of the whole society is bigger and bigger. To improve the level of electricity service and meet user demand for electricity, power grid companies must work to change the structure of power grid development, establish and develop smart grids. In order to guarantee the rapid and stable development of the smart grid, in the process of the smart grid construction, to strengthen the understanding of smart grid, key technologies, to maintain the stability of the smart grid development, promote the stable operation of the smart grid has very important practical significance.The integration of distribution network in a smart grid environment regulation is to ensure the reliable operation of power grids, to achieve distribution network scheduling and monitoring a feasible model of integration management. Integration of distribution network in this paper, the smart grid environment control principle and some problems of the distribution network dispatching, and make related to the realization of the integration of distribution network control is introduced.
\end{abstract}

Keywords- Electricity; Smart Grid; Quality; Distribution Network; Management (key words)

\section{INTRODUCTION}

Smart grid is the grid intelligent (electric power), also known as the "grid" 2.0, and it is based on the integration, high-speed bidirectional communication network. Through the use of advanced sensor and measuring technology, advanced equipment technology, the advanced control method, and the application of advanced technology of decision support system, it realize the grid reliability, security, economic, efficient, environmentally friendly and use safety goals. Its main features include self-healing, incentives and include user, against attacks, provide meet user requirements of power quality in the 21st century, allow all sorts of different power generation in the form of access, start the electric power market and the optimization of assets run efficiently[1].

The smart grid is the inevitable developing trend of power grid technology. The communication, computer, automation technology has extensive application in the power grid, and organic combination with traditional electric power technology, and greatly improve the intelligent level of the power grid. Sensor technology and information technology application in the power grid, the system state analysis and auxiliary decision provides the technical support, make it possible to grid self-healing. Scheduling technology, automation technology and the mature development of flexible transmission technology, for the development and utilization of renewable energy and distributed power supply provides the basic guarantee. The improvement of the communication network and the popularization and application of user information collection technology, promote the two-way interaction with users of the grid. With the further development of various new technologies, application and highly integrated with the physical power grid, smart grid arises at the historic moment.

Development of smart grid is the inevitable choice of social and economic development. In order to achieve the development of clean energy, transport and given power grid must increase its flexibility and compatibility[2]. To withstand the increasingly frequent natural disasters and interference, intelligent power grid must rely on means to improve its security defense and self-healing ability. To withstand the increasingly frequent natural disasters and interference, intelligent power grid must rely on means to improve its security defense and self-healing ability. In order to reduce operating costs, promote energy conservation and emissions reduction, power grid operation must be more economic and efficient, at the same time must to intelligent control of electric equipment, reduce electricity consumption as much as possible. Distributed generation and energy storage technology and the rapid development of electric cars, has changed the traditional mode of power supply, led power flow, information flow, business flow constantly fusion, in order to satisfy the demands of increasingly diverse users.

Intelligent distribution network is one of the key links in the smart grid. Usually $110 \mathrm{kv}$ and below power network belongs to the distribution network, power distribution network is the entire power system and the dispersion of the user directly connected parts. Intelligent distribution network system is the use of modern electronic technology, communication technology, computer and network technology, the power distribution network data online and offline data, distribution network data and user data, power grid structure and geographical graphics information integration, the realization of power distribution system under normal operation and accident 
monitoring, protection, control, power, and the intelligent power distribution management[3].

Intelligent distribution network in the country is still in its infancy, the current domestic urban distribution network feeder automation rate is less than $10 \%$, is still in its pilot has just started and the preliminary construction stage. As countries increase the smart grid construction, intelligent distribution network will become the country electric power industry a new round of investment priorities, wide space of market in the future. Distribution network automation began in 2009, from the beginning of the five pilot cities expanded in 2012 to more than 40 cities. According to the national power grid planning, due to the feeder rate, power supply reliability of the pilot cities have markedly improved, a total of about 300 cities in China will start during the 12th five-year construction of distribution network automation. "Twelfth five-year" period according to the distribution network intelligent rate of $40 \%$ measured distribution of intelligent terminal and host total market capacity will reach 23 billion yuan and 3.6 billion yuan, total market capacity of nearly 28 billion yuan. In the next few years, there will be huge distribution automation potentials for growth.

\section{THE KEY TECHNOLOGY OF THE SMART GRID}

Intelligent distribution network system with electrical automation system by the master station, communication system, automatic monitoring device of three parts, forming a complete information transmission and processing system, realize the remote management of distribution network operation[4]. For intelligent distribution network system, the three parts in the communication system is the key and core to realize data transmission, and the communication systems will be the main control command accurately transmitted to the remote terminal, and the distance data collected from the control center of equipment operation. Intelligent distribution network communication system may consist of a variety of communication, mainly USES the optical fiber and power carrier communication mode.

At present, a preliminary framework of the smart grid system has formed in the construction aspect of the smart grid, has formed, its architecture is shown in Fig.1

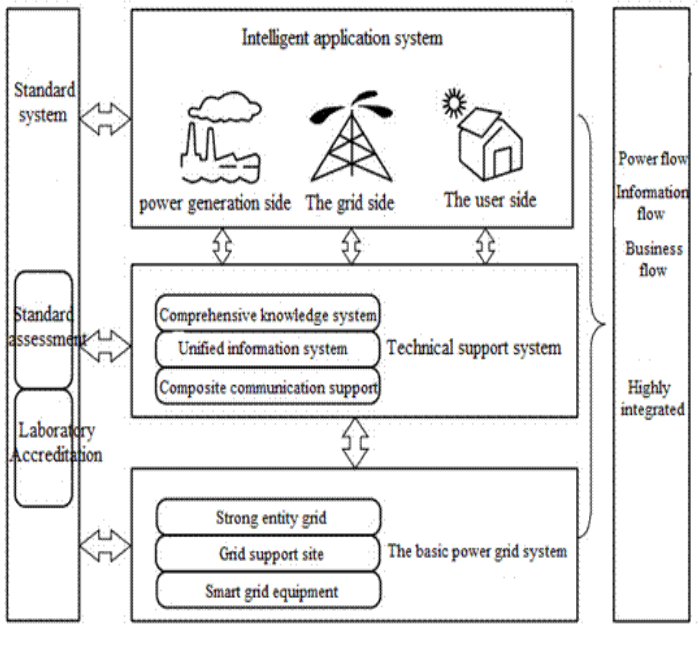

Figure 1. Strong smart grid architecture

\section{A. The flexible distribution network topology}

Distribution network topology structure is the foundation of the smart grid construction. Through the distribution network topology structure, researchers can make the distribution network in the event of a failure, the failure impact of reduced to the lowest level, and the ability to quickly and contact the smart grid addition to other part of the recovery of the fault in the area of power supply. Currently, the new concept of distribution in the network topology: bidirectional current, power exchange between each circuit implementation; DC ring bus, a new form of service; circular low-voltage distribution, a new reconstruction choice; integrated distributed energy, flexible micro nets, deliberately safety island [5].

\section{B. Intelligent information technology}

In the process of the development of smart grid, smart information technology to the construction of the smart grid is one of the most important contents and supports, it transforms from power plants to transmission and distribution, and dispatches the electricity to every link, and provides an important guarantee for the stable operation of the smart grid. From the aspects of the smart grid, intelligent information technology basically has the following three important characteristics: digital is far more than the current grid digital degree; through the use of SOA (service-oriented architecture) for data integration and application, and through the SOA build a unified information platform; to further applications scheduling management, electric power marketing, human resources and the production management and related auxiliary decision information, to build business integration, the information focus, in line with the smart grid operation rule, can extend application analysis system, so as to realize the production, scheduling, marketing and other related business information storage and management, to form a complete set of the integrated system with intelligent decision-making, comprehensive query and management for power grid system provides reliable data to make decisions.

\section{Intelligent communication technology}

In order to ensure the real-time control of smart grid and realize the dynamic management of smart and highly effective grid, the two-way real-time communication system must be established, so as to make the smart grid a real-time, dynamic modern power infrastructure[6]. The system can not only complete the smart grid internal data detection, but also can adjust the smart grid, internal data, and achieve the intelligent management of power grid. At the same time, through the system, it can implement various parts of the grid and the remote control, testing various disturbances in the grid, and compensation, at the same time can also realize the tide redistribution, thus ensuring the safety of the smart grid. Through the intelligent communication system, also can realize all kinds of intelligent electronic equipment, all kinds of smart meters, circuit controller, the control center, network communication between the user and protection system, really raise people for grid control ability, raise the level of power system service to the user. 


\section{The technology of distribution electricity access}

Distribution power mainly includes distribution in different parts of the smart grid power generation device and the energy storage device, through into the smart grid, power plants to complete the addition to the smart grid electricity, the energy storage device of a smart grid through into the smart grid can temporarily surplus to store electrical energy. At present, the distributed power generation technology mainly includes wind power, solar photovoltaic power generation, fuel cell, micro gas turbine, biomass energy, tidal energy, geothermal energy, nuclear energy power generation technology. Distribution of energy storage device includes the superconducting energy storage and flywheel energy storage, battery energy storage. In distribution network, due to the relatively close to the power supply and load distribution center, therefore no longer requires the expansion of the power grid greatly, also makes the reliability of power supply secured, if big grid suffered severe damage because of various reasons, the distribution of the power supply can be formed piconets or island for hospitals, television stations and other important user and equipment to provide irritability power supply[7].

\section{E. The technology of measuring the number}

In the process of construction and operation of smart grid, the number of measuring technology is an important means to ensure the normal operation of the smart grid, and the smart grid is the most basic elements. Through the modern quantity measurement technology, people have access to information about each part in the smart grid, and convert it to data information, and the number of ginseng by modern measuring technology can realize the smart grid running status of equipment is stable, real-time monitoring of power grid is complete and provided to each part of the smart grid and to use. Through modern quantity measurement technology, for all kinds of table in the smart grid, a program to read data assists to complete the circuit of power grids blocked unblock, completed a review of electricity, to avoid power, leakage phenomenon. Through modern quantity measurement technology, can realize with the electricity customer interaction and communication between the listen to the opinions of the users of electric power service, and create conditions to provide better service.

\section{F. Intelligent scheduling technology}

Intelligent scheduling technique is the important guarantee to realize the smart grid intelligent scheduling, and to realize the power generation system, transmission system, substation system, distribution system and power system between the bridge and the link to contact each other. Intelligent scheduling technology of ascension integrates with and promotes the WAMS system, various system functions such as EMS system, construction of unified network database, gradually establish a guarantee the smart grid coordinate operation platform for the integration of scheduling, ensure the operation of the smart grid security and stability control is of great importance.

\section{G. Advanced power electronics technology}

High power electronic equipment is mainly including IEDS (intelligent electronic device), multi-function solid- state switch and flexible transmission system device. In the process of the smart grid operation, there are a large number of IEDS, multifunction solid-state switch device and flexible transmission system in working, through IEDS, multifunction solid-state switch, and the flexible transmission system devices can improve the quality and control of power across the smart grid, to ensure that the user will be able to get normal good quality of power. At the same time, the power electronic equipment is the key to each energy conversion in the smart grid system, in the smart grid plays an important role in energy conversion. In the current, as the advanced technology of the smart grid is still there are many technical bottleneck, also for widespread use. But, as the information technology, communication technology, electronic power technology and control technology and the development of intelligent technology, smart grid technology will get fast development, and also will be applied to the national production and life of the country.

\section{THE CURRENT DISTRIBUTION NETWORK SCHEDULING PROBLEMS ANALYSIS AND COUNTERMEASURES}

\section{A. Technical problems and countermeasures}

The information management application requirements and the interactive mode of distribution network between system needs to be clear distribution network automation system should be in terms of graphics, models, data and the superior control automation system, the share of geographical information management system to form longitudinal or transverse relationship. In the real operation of distribution network automation system in terms of information sharing and data integration still has very big development space, also can more fully the application of distribution network dynamic data and static information. Operation each link of production, operation and dispatching, the distribution deal with sufficient demand for data and application of deep excavation, and on this basis to promote the information interaction between each system use, improve the overall level of distribution management.

In the present distribution network automation system, standing side by way of giving information classification is an unclear, primary and secondary classification problem. This makes the accident cases, the mass sending key information and secondary information, interfere with the operation personnel to determine accurately and timely in an emergency power grid failure, affect the timely processing of the accident. Therefore, the distribution network automation system shows the information which should make appropriate optimization, and makes its sending information to stand side, according to the classification and grading of transmission equipment to do the corresponding information block processing. At the same time, the system will divide the window shows the accident information, abnormal information, etc., to make the operation personnel can not only reduce the daily work but also in accident cases judgment information quickly[8].

\section{B. Management problems and countermeasure}

Establishing system application evaluation system comprehensively promotes the application level of 
distribution network system in application level and the relevant management still exist some problems. To solve these problems and can be applied in the evaluation standard and application of measures for the management of distribution network automation system, formulate the related content, to promote the overall distribution network automation system application level and management level has increased, so as to raise the level of power supply and improving the quality of the power supply.

As the distribution network automation system and production management system of information interaction between growing demands, a lot of works need to rely on the information platform of the company. At the same time, the present customers with site construction and renovation projects organized by the Marketing Department are responsible for the preliminary design needs the company various departments related to master this sync. For this purpose, the power grid company's production department should be in the planning, design, construction and scheduling department each link form good communication mechanism, and along with all the information related to the Marketing Department of science and technology into the mechanism, avoid to cause the blank of communication and management[9].

\section{THE REALIZATION OF THE INTEGRATION OF DISTRIBUTION NETWORK CONTROL}

With the continuous development of the country electric power system, power company management of distribution network is becoming more and more attention, not only in the department set up adjustments, and inclining on related investment. At the same time, in order to solve the problem of distribution network in the country is weak, since 2010, the state grid also made relevant instructions, determined to strengthen the construction of smart grid, also requires a unified planning of the distribution network system, in order to solve the problem, related to promote intelligent power grid.

\section{A. The construction of distribution network automation}

pointed out the direction of the intelligent distribution network for construction of distribution network automation, distribution network integration is a necessary means to the realization of intelligent distribution network, construction of intelligent power distribution network as a whole train of thought, in building a strong network frame, on the basis of the distribution network with a single equipment automation, intelligent terminal, and distributed storage, distributed power supply access to realize intelligent distribution network, and to achieve a digital description of distribution network, including power distribution network based on topology, power distribution equipment (parameters, status, characteristics, etc.), distributed power supply, distributed energy storage, such as static digital description, operation and control and monitoring, based on the distribution network dynamic digital description of distribution network automation function.

\section{B. Information system integration}

On the basis of the existing information system, the construction and overall implement PMS, GIS, OMS, ERP, the integration between the information sharing between each system through the data center. Expand the application of the system such as PM S function, the strong support of production management informatization, and improve the power grid of the lean management information platform. At the same time, strengthen the PMS, GIS the application of the system in distribution network, unified and account of graphics equipment, and equipment operation and maintenance management work process, make the distribution equipment management, operation management, such as unification of information management, standardize the production operation process, business personnel to promote the standardization of production management and the lean level.

\section{Improve the power grid structure}

Adhere to the principle "providing a stable and reliable distribution network", to distribution network partitioning layered comb, focus on starting from optimizing the structure of power grid, the distribution network more contact space truss structure, improve the user's electricity reliability. In the distribution network system, in order to reduce the line segment and the impact of connection mode of power supply and utilization, the implementation of the scientific and reasonable wiring is a choice. It can not only improve the quality of power supply, but also obtain good social benefit and economic benefit. The implementation of scientific and reasonable wiring is not only to increase the source of the layout, but also to the rationality of the segment or interconnected space truss structure adjustment, so as to guarantee the reliability of the power distribution network system[10].

\section{The distributed power/energy storage access}

National clean energy development strategy, how to make all kinds of distributed power supply connected to existing power system, has become a research topic for the electric power enterprises. Research on the distributed power supply access technology is an action of energy conservation and emissions reduction on the support, for the next phase of parallel operation, monitoring and dispatching of the power station to provide a system, perfect technical reserves, train the ability of for distributed power plant monitoring, scheduling, lay a good foundation for the development of smart grid, and help explore a promotion significance of technical solutions and management mode.

\section{CONCLUSION}

With the development of electric power system, the intelligent power grid system has got great progress. Intelligent grid system for electric power transmission and management in China has brought a lot of conveniences. In order to solve the problems of intelligent power grid scheduling and monitoring system, of the integration of distribution network in a smart grid environment regulation also was established and gradually formed. The establishment of this system makes the distribution network system scheduling and monitoring of mutual cooperation, reduces unnecessary personnel, and give full play to the advantages of the smart grid system.

\section{REFERENCES}

[1] M.Cai. Hubei of smart grid, the key technology research [J]. Journal of Hubei electric power. 2011, 35 (05):14-18. 
[2] J.S.Yan. The progress of the smart grid and the key technology of review $[\mathrm{J}]$. Journal of anhui technical college of electrical engineering. 2011, 10(02):24-28.

[3] J.H.Yu ,H.Zhou. Present Situation and Prospects of China's wind power development $[\mathrm{J}]$. Automation of electric power systems, 2011,.39(2).13-18.

[4] T.S.Bi, S.M.Liu. The implications and implementations of smart grid in different countries[J]. Journal of North China Electric Power University: Natural Science Edition, 2011, 38(2):1-9.

[5] J.Q.Shuai. Construction of smart grid innovation development: east China advanced dispatching center project of construction of practice $[\mathrm{J}]$. Electric power enterprise management in China. 2009, 23(4):62-66.
[6] J.D.Li. The problems in the operation of the scheduling problem and countermeasure analysis $[\mathrm{J}]$. Power technology application. $2013,10(2): 93-94$

[7] Y.Guo, J.Zhou, Introduction to the smart grid integration mode of distribution network regulation $[\mathrm{J}]$. Science and technology entrepreneurs, 2012,8 (11) : 121-125.

[8] N.H.Li, Y.X.Ni, S.J.Sun. Survey on smart grid and relevant key technologies[J]. Southern Power System Technology, 2010, 4(3): $1-7$.

[9] C.Yu, N.N.Zhai. Evaluation of TOU price oriented to smart grid[J]. Power System Protection and Control, 2010, 38(21): 196-214.

[10] B.Li, Z.Q.Bo. Investigation on protection and control of smart grid[J]. Automation of Electric Power Systems, 2009, 33(20): 7-12. 